\title{
RETRACTED ARTICLE: Inspection of design defects of big multimedia data electronic products based on Bayesian network inference model
}

\author{
Yan Zhang ${ }^{1} \cdot$ Rui Zhang ${ }^{2} \cdot$ Wei Kang ${ }^{3}$
}

Received: 9 November 2017 /Revised: 22 November 2017 / Accepted: 23 November 2017 /

Published online: 20 December 2017

(C) Springer Science+Business Media, LLC, part of Springer Nature 2017

The Editor-in-Chief has retracted this article [1], which was published as part of special issue "Multi-source Weak Data Management using Big Data", because there was evidence suggesting authorship manipulation and an attempt to subvert the peer review process.

Author Yan Zhang agrees to this retraction. Authors Rui Zhang, and Wei Kang have not responded to correspondence about this retraction.

\section{References}

1. Zhang, Y., Zhang, R. \& Kang, W. Inspection of design defects of big multimedia data electronic products based on Bayesian network inference model. Multimed Tools Appl (2017). https://doi.org/10.1007/s11042-017-5455-6

Electronic supplementary material The online version of this article (https://oi.org/10.1007/s11042-0175455-6) contains supplementary material, which is available to authorized users.

Yan Zhang

zhangyan1778@126.com

Rui Zhang

ruizhang@126.com

1 Shandong University of Finance and Economics, Jinan, Shandong 250000, China

2 Shandong Provincial Institute of Electronic Information Products Inspection, Jinan, Shandong 250000, China

3 An-Bai Science and Technology (Beijing) Co., Ltd., Beijing 100000, China 